\title{
LOS MITOS LATINOAMERICANOS: VIGENCIA DE LA OBRA DEL BUEN SALVAJE AL BUEN REVOLUCIONARIO
}

\author{
Leonardo Favio Osorio* \\ http://orcid.org/0000-0001-6512-6382
}

RECIBIDO: Marzo 2019 / ACEPTADO: Octubre 2019 / PUBLICADO: Mayo 2020

\begin{abstract}
Como citar: Osorio, Leonardo Favio (2020). Los mitos latinoamericanos: vigencia de la obra "Del buen salvaje al buen revolucionario". Telos: revista de Estudios Interdisciplinarios en Ciencias Sociales, 22 (2), Venezuela. (Pp.310-324).

DOI: www.doi.org/10.36390/telos222.05
\end{abstract}

\section{RESUMEN}

Las sociedades latinoamericanas están llenas de mitos políticos construidos a lo largo del tiempo. Carlos Rangel (2006) en su libro "Del buen salvaje al buen revolucionario", se propuso denunciar muchas de esas falacias elaboradas sobre todo por sectores vinculados al pensamiento marxista. En ese sentido, este trabajo tiene como objetivo realizar un análisis de esa importante obra con gran vigencia en la actualidad. El autor analiza varios mitos, entre ellos: La pureza de las sociedades indígenas, la leyenda negra sobre el conquistador hispano, la aceptación del marxismo como teoría en defensa de los desfavorecidos, el imperialismo como causa del atraso de la región, son solo algunos de las muchas retóricas equivocadas presentes en América Latina. Fue utilizado el método analítico-sintético, la hermenéutica y la heurística para la interpretación del texto. Se concluye que gran parte de los mitos analizados por Carlos Rangel en su texto se mantienen vigentes en Latinoamérica, se busca todavía construir nuevas utopías sobre la base de los mitos indígenas del buen salvaje para lograr la igualdad social, con un discurso antioccidental y antimperialista que solo ha servido para justificar varios despotismos en el continente en nombre de una revolución.

Palabras clave: Carlos Rangel, mitos políticos, Latinoamérica, imperialismo, marxismo.

\section{Latin American myths: Validity of the work "Del buen salvaje al buen revolucionario"}

\section{ABSTRACT}

Latin American societies are full of political myths built over time. Carlos Rangel in his book "Del buen salvaje al buen revolucionario", proposed to denounce many of those fallacies elaborated

\footnotetext{
* Licenciado en Educación. Mención: Historia. Summa Cum Laude. Magister Scientiarium en historia de Venezuela. Doctor en Ciencias Humanas de la Universidad del Zulia. Responsable del proyecto de Investigación titulado: Poder, negocios y rivalidades locales en el proceso de consolidación del Estado en Venezuela (Siglos XIX-XX), que forma parte del programa de investigación: El ciudadano construye su historia: Reconstrucción del imaginario, uso del espacio, procesos y socioeconómicos y políticos (Siglos XIX-XXI), Financiado por el Consejo de Desarrollo Científico y Humanístico de la Universidad del Zulia (CONDES). Autor de varios artículos científicos publicados en revistas nacionales y extranjeras. Ganador del premio de Historia Agustín Millares Carlos 2015. Correo electrónico: leonardofavio87@gmail.com
} 
especially by sectors linked to marxist thought. In that sense, this work aims to perform an analysis of this important work with great validity today. The author analyzes several myths, among them: The purity of indigenous societies, the black legend about the Hispanic conqueror, the acceptance of marxism as a theory in defense of the disadvantaged, imperialism as a cause of the backwardness of the region, are just some of the many wrong rhetoric present in Latin America. The analytical-synthetic method, hermeneutics and heuristics were used to interpret the text. It is concluded that a large part of the myths analyzed by Carlos Rangel in his text are still valid in Latin America, we are still looking to build new utopias based on the indigenous myths of the good savage to achieve social equality, with an anti-Western and anti-imperialist discourse that it has only served to justify several despotisms on the continent in the name of a revolution.

Keywords: Carlos Rangel, political myths, Latin America, imperialism, marxism.

\section{Introducción}

Los textos clásicos tienen la particularidad de ser capaces de dar respuestas a problemas actuales. Son obras que siempre tienen mucho que ofrecer para explicar realidades complejas, cuya raíz se encuentra muchas veces en el estudio del pasado de las sociedades.

Así es como la obra insigne de Carlos Rangel, ${ }^{1}$ (2006) "Del buen salvaje al buen revolucionario", tiene gran vigencia para explicar no solo parte de los mitos latinoamericanos, sino del tercer mundo en general. De hecho, llegó a publicar un libro llamado el tercermundismo, asumiendo que existen dilemas generales no superados por las denominadas sociedades en desarrollo (Rangel, 1982).

Este trabajo está centrado solo en el texto del buen Salvaje al buen revolucionario, por ser la principal obra del autor que contiene sus más importantes planteamientos sobre ideas que han circulado en Latinoamérica en general. En ese sentido, el trabajo tiene como objetivo realizar un análisis de esa importante obra con gran vigencia en la actualidad. Fue utilizado el método analítico-sintético, la hermenéutica y la heurística para la interpretación del texto. Pese a su relevancia, ese libro no ha recibido la atención ni el debate necesario por parte de los académicos en la región, menos aún en Venezuela que es su país de origen.

El problema ha sido uno de los planteamientos realizados por el mismo Rangel, el predominio de ideas de corte marxista, que buscan siempre en algún explotador la culpa de todos los males pasados, presentes y futuros. Las tesis que ofrecen una visión más oscura de las sociedades, son mucho más difíciles de asimilar.

Por eso fue valiente e innovador su escrito, por la preponderancia para ese momento de la teoría de la Dependencia, el volátil clima antiyanqui y procomunista todavía marcado por la Revolución cubana y la Guerra Fría, en ese escenario no era frecuente que los intelectuales se atrevieran a emprender análisis de corte liberal o críticos del marxismo, reconociendo el valor de la democracia o el capitalismo norteamericanos (Almandoz, 2019).

\footnotetext{
${ }^{1}$ Carlos Rangel nació en Caracas, en 1929. Cursó estudios superiores de literatura comparada en Estados Unidos y Francia, y ha sido profesor de Lengua y Literatura Española e Hispanoamericana en la New York University y de Periodismo informativo y de opinión en la Universidad Central de Venezuela. Después de haber servido como Primer Secretario de la Embajada de Venezuela en Bélgica, asumió, en 1959, la Sub-dirección del semanario caraqueño Momento, dando inicio a una importante labor como analista político en la prensa nacional. Paralelamente, ha sido, desde 1960, uno de los principales promotores de los programas de opinión en la televisión venezolana (Rangel, 2006).
} 
Muchas de las advertencias y críticas de Rangel no fueron escuchadas. Las sociedades construyen mitos a lo largo de su historia, es mucho más sencillo asimilar visiones idílicas, por lo cual los nacionalismos siempre se construyen sobre la base de elementos positivos para lograr crear solidaridad sobre la nación. Por el contrario, los análisis que destacan los errores de las sociedades, y ponen énfasis en su propia responsabilidad a la hora de no alcanzar los grandes objetivos nacionales, producen un natural e instintivo rechazo en los hombres.

Los intelectuales pese a ser supuestamente más racionales en la construcción de sus teorías, son a veces ingenuos en sus análisis y se dejan obnubilar por las emociones y la carga valorativa sobre sus sociedades. En este momento que transita Venezuela, marcada por el totalitarismo socialista, no deja de haber quienes intentan salvar sus responsabilidades ante la debacle actual. Pero nuestros problemas contemporáneos no se pueden entender sin asumir una posición crítica sobre nuestro devenir como nación.

Una sociedad que eligió voluntariamente a Hugo Chávez para la presidencia de la República, a pesar de mantener un discurso cargado de resentimiento y revanchismo hacia diferentes sectores, lógicamente padece de ciertos traumas históricos que no han sido suficientemente explicados. Lo mismo ha pasado con otros países latinoamericanos donde llegó al poder el socialismo del siglo XXI. El texto de Carlos Rangel fue un llamado de atención en su momento sobre el predominio de ciertas ideas que mantuvieron a la región presa del atraso histórico.

Se analiza varios tópicos en la obra de Carlos Rangel, entre ellos la tergiversación del pasado colonial que sirve para vender la visión del buen salvaje al buen revolucionario, la condena al imperialismo, y el auge de las ideas marxistas y socialistas en Latinoamérica. Por último se estudia la vigencia de su pensamiento en el contexto actual.

\section{1.-La construcción de mitos históricos en Latinoamérica: el pasado colonial y la visión del Buen salvaje}

Carlos Rangel hace realmente una lectura sociológica sobre el malestar de las sociedades latinoamericanas. Un ensayo histórico y social que intenta develar la recurrencia de errores y fracasos pero que son revestidos de proezas revolucionarias o hazañas no culminadas.

Isaac Serfaty explica que los mitos políticos son un recurso retórico de una gran eficacia pragmática usado tradicionalmente por gobiernos populistas y totalitarios (Serfaty, 2010). La función de todos los mitos es la de estructurar a las sociedades, la de darles referentes que les sostengan a través del tiempo, no admite debates ni contradicciones (Altez, 2011, p. 49).

Ante el peligro y los usos que principalmente han realizado los marxistas de los mitos latinoamericanos, era necesario desmontar muchas de las falacias construidas a lo largo del tiempo para justificar los fracasos sociales. De esa forma en la introducción de su texto Carlos Rangel expone que "LOS LATINOAMERICANOS no estamos satisfechos con lo que somos, pero a la vez no hemos podido ponernos de acuerdo sobre qué somos, ni sobre lo que queremos ser. ¿En qué consiste, exactamente, ese ser latinoamericano que compartimos desde el Río Bravo hasta la Patagonia?" (Rangel, 2006, p. 20).

Es un análisis de imaginario sociológico, ¿cómo se han definido las sociedades latinoamericanas? Es una pregunta que marca todo un hilo expositor dirigido a realizar un 
adecuado diagnóstico de muchos mitos prevalecientes en el continente. Exponer los complejos de los que han sido víctimas los pueblos americanos.

La mezcla cultural y el pasado colonial son factores históricos que "...tienden a confundir la conciencia del continente, inyectándole elementos de indefinición, mitología, racismo, complejos de culpa y de inferioridad, etc" (Rangel, 2006, p. 21). He allí el meollo del problema, los complejos de víctimas se han desarrollado a partir de una lectura sesgada del pasado histórico.

El autor pone el énfasis en el pasado colonizador, estudia solo la América hispana, es decir, a los pueblos americanos conquistados por los españoles. A pesar de su heterogeneidad, reconoce que "La América Española en cambio, a pesar de su inmensidad geográfica y su aparente heterogeneidad, es un conjunto identificable, con suficientes rasgos comunes como para que sea útil generalizar sobre él, una subdivisión "clara y distinta" del mundo en que vivimos" (Rangel, 2006, p. 23).

Si bien es muy osado intentar esbozar problemas generales de una región tan diversa como América Latina, no deja de ser cierto que es posible identificar rasgos generales, con los matices de cada caso, capaces de explicar el subdesarrollo del continente. Las lecturas históricas son las primeras que han permitido establecer diferentes mitos comunes.

La visión del Buen salvaje es la idea de la que parte Carlos Rangel en su texto, por ello señala que:

Buscando lo que pre-existía en su deseo, los descubridores crearon el mito más potente de los tiempos modernos: "El Buen Salvaje, versión "americanizada" o "americanista" del mito de la inocencia humana antes de la caída, fábula destinada a tener inmensa fortuna en la historia de las ideas, y desde luego igualmente inmensas consecuencias (Rangel, 2006, p. 33).

Esa visión del buen salvaje había sido expuesta por Rousseau, al asumir que el hombre era bueno por naturaleza pero la sociedad era quien lo corrompía (Rousseau, 2000). El indigenismo surgido en el siglo XX explotaría con gran fuerza la tesis del indígena "puro", que fue víctima de la opresión del pueblo europeo. Ya desde el siglo XIX la leyenda negra habría tratado de explotar la visión negativa del pasado colonial y de la inocencia de los pueblos indígenas hoy americanos.

Lo cierto es que el europeo se apoyó en esa visión romántica en los inicios del proceso de conquista, creyó ver y constatar que en efecto hombres incontaminados por la civilización, han permanecido inocentes (Rangel, 2006). El idealismo forma parte de todas las sociedades, el anhelo de conseguir un orden social carente de las contradicciones presentes en la mayoría de los pueblos del mundo.

Los americanos se apoyaron en esa visión del buen salvaje para oponerse al "yugo" colonial. Como expone Carlos Rangel,

Por causa del mito del Buen Salvaje, Occidente sufre hoy de un absurdo complejo de culpa, íntimamente convencido de haber corrompido con su civilización a los demás pueblos de la tierra, agrupados genéricamente bajo el calificativo de "Tercer Mundo", los cuales sin la influencia occidental habrían supuestamente permanecido" (Rangel, 2006, p. 36). 
Vicios como el egoísmo, la mercantilización de las relaciones sociales, la esclavitud, y tantos otros defectos se incorporaron a estas sociedades a través de la colonización europea. Se obvia de esa forma todo lo positivo que trajo el aporte occidental. Todavía en la actualidad en los discursos políticos o indígenas se insta a Occidente a pedir perdón por la conquista de América.

Es difícil asumir la América hispana solo como parte de una herencia histórica, ya que es producto de una mezcla cultural. Pero pervive el maniqueísmo, como expone Serge Gruzinski "las aproximaciones dualistas y maniqueas seducen por su simplicidad y, cuando se escudan en la retórica de la alteridad, confortan a las conciencias al tiempo que satisfacen nuestra sed de pureza, de inocencia y de arcaísmo" (Gruzinski, 1999, p. 48).

El mito de la pureza indígena y el conquistador visto como villano, tergiversa la historia. Pero es mucho más loable identificarse solamente con las víctimas y no con los opresores. Hay a su vez un complejo de víctima y uno de vergüenza por ser el resultado de un proceso traumático para las sociedades originarias.

De esa forma Carlos Rangel explica que los latinoamericanos somos a la vez descendientes de los "conquistadores y del pueblo conquistado, de los amos y de los esclavos, de los raptores y de las mujeres violadas. El mito del Buen Salvaje nos concierne personalmente, es a la vez nuestro orgullo y nuestra vergüenza" (Rangel, 2006, p. 39-40).

Es la contradicción del discurso, reivindicar un ser americano diferente al colonizador español, y apoyar todas las cruzadas que buscan restituir la antigua "gloria americana", ya sea luego con el mito de la independencia o con la supuesta armonía en la que vivían la mayoría de las etnias indígenas americanas.

La tesis del buen salvaje lleva entonces al buen revolucionario, al de buscar un cambio profundo para entonces finalmente volver a ese estado idílico original. La mayoría de los proyectos esbozados recientemente por los gobiernos que impulsaron el socialismo del siglo XXI, se basaron precisamente en esa idea de revalorar el pasado indígena en contraposición a la herencia europea occidental.

Los nuevos héroes serán quienes se atrevieron a enfrentar el llamado imperio español durante las independencias, y de más reciente data, el imperialismo de los Estados Unidos. Lo importante es construir una retórica en la que los latinoamericanos nunca sean responsables de los fracasos o problemas históricos de sus sociedades. No se menciona nunca como las sociedades indígenas también vivían en permanentes conflictos entre sí, y lejos de ser prósperas, tenían muchas penumbras. Pero esas contradicciones no son explicadas.

La teoría de la dependencia en el siglo XX caló perfecto en Latinoamérica porque responsabilizaba del subdesarrollo a terceros países, siempre hay un opresor con el cual luchar y a quien culpar de todos los males. Nunca se acepta el fracaso debido a causas internas, siempre debe haber un enemigo exterior. La lectura sesgada del pasado colonial permite culpar a los europeos de los males actuales de América Latina.

\section{El problema del imperialismo en la obra de Carlos Rangel}

El siglo XX fue el de la retórica antiimperialista, era el auge del texto de Lenin sobre el imperialismo como fase superior del capitalismo (Lenin, 2000). Fue un discurso que permitió una renovación muy profunda del drama latinoamericano, tenían ahora un nuevo enemigo al cual vencer y superar para ser libres. 
La retórica antinorteamericana superó incluso al discurso antiespañol, que siempre ha estado presente y recordada sobre todo durante las celebraciones del descubrimiento de América o día de la raza, hoy rebautizado como día de la resistencia indígena en algunos países para exacerbar el resentimiento histórico.

Carlos Rangel bien explica este importante tópico del imperialismo americano para justificar el fracaso. El autor bien aclara que "El imperialismo norteamericano en América Latina no es, desde luego, ningún mito. Sólo que es una consecuencia y no una causa del poder norteamericano y de nuestra debilidad" (Rangel, 2006, p. 57). Efectivamente, ha existido una política expansionista, y en algunos casos, al igual que con la colonización española, ha implicado el saqueo y anexión por la fuerza de algunos pueblos.

El problema ha estado en usar esos hechos para justificar entonces la falta de prosperidad de las naciones Latinoamericanas. El otro asunto es la permanente condena al intervencionismo americano en el continente. Aunque este muchas veces ha sido solicitado bajo determinadas circunstancias.

Carlos Rangel explica que en cada país latinoamericano ha habido siempre adversarios de los gobiernos (o traidores potenciales, en las propias filas de los gobiernos) dispuestos casi literalmente a cualquier cosa con tal de llegar al poder, o por lo menos derrocar al gobierno establecido; y listos por lo mismo a aceptar y aún a solicitar activamente la intervención, la ayuda o por lo menos la neutralidad positiva de la potencia protectora del Hemisferio (Rangel, 2006, p. 74-75).

Es el doble discurso, las intervenciones no son del todo condenables bajo ciertas circunstancias. En Cuba por ejemplo, pese a la retórica antimperialista, muchos cubanos opuestos a Fidel Castro anhelaron la intervención de Estados Unidos para poner fin al totalitarismo castrista. Hoy Venezuela, o algunos sectores de la población, tolerarían una intervención americana con tal de salir de la tiranía chavista.

Sin embargo, los gobiernos latinoamericanos en general han expresado su resistencia a cualquier forma de intervención americana, sobre todo para garantizar sus propios intereses. Esto se justifica bajo el manto de la defensa de la soberanía, que ha servido para poder mantener la tiranía en el continente sin intervención de otros países.

Ante variadas intervenciones que tuvieron los Estados Unidos en el continente, se explica siempre como una ofrenda a los países. De esa forma Mará Elvira Roca argumenta que:

El antiamericanismo triunfa porque es una coartada perfecta para eludir la responsabilidad. Justifica el fracaso de muchas sociedades y evita asumir responsabilidades personales y colectivas en ese fracaso. El negocio de la irresponsabilidad es fundamental para entender el éxito siempre arrollador de las propagandas antiimperiales. Vender irresponsabilidad ha sido siempre muy lucrativo. Que la culpa sea de otro es descansado. Alivia el alma y nos evita muchos quebraderos de cabeza y mucho esfuerzo (Roca, 2018, p. 108).

En realidad el discurso antiamericano y antiimperialista es fácil de aceptar por razones psicológicas usadas para negar problemas complejos. Decir que unos son pobres porque otros países son ricos, ha sido un mito muy extendido por el marxismo. Ante ese planteamiento, es 
lógico pensar que el país más poderoso del mundo, Estados Unidos, lo es únicamente gracias a la explotación de Latinoamérica y en general de todos los países del tercer mundo.

Esto mismo sostiene Carlos Rangel cuando explica que "Sin el desarrollo norteamericano, no habría subdesarrollo latinoamericano. Sin el subdesarrollo latinoamericano, no había desarrollo norteamericano, etc" (Rangel, 2006, p. 78-79). Así de simplista resulta ese razonamiento. Pese a la debilidad obvia de tal proposición, su aceptación ha sido casi universal en las academias y discursos políticos de Latinoamérica. Jean-Françis Revel en su texto "La obsesión antiamericana", señala que "la falsedad nunca ha impedido prosperar a una opinión, cuando va apoyada por la ideología y protegida por la ignorancia. El error, cuando satisface una necesidad, rehúye los hechos" (Revel, 2003, pp. 8-9).

Los hechos son desestimados o manipulados cuando lo importante es producir una teoría que alivie los complejos de las sociedades, sus frustraciones y resentimientos. Las relaciones económicas de Latinoamérica con Estados Unidos siempre se han visto desde la lógica de suma cero, los norteamericanos se han llevado las riquezas nacionales. Nunca hemos reconocido los beneficios del intercambio económico y las inversiones en América Latina por las empresas de la potencia del norte. La región se ha visto beneficiada de ese comercio, pero se ha preferido mantener la retórica de que las empresas trasnacionales son las causantes de su pobreza, aunque sus inversiones sean las más importantes, y los salarios pagados sean lo mejor a lo que puede aspirar alguien que vive en el tercer mundo.

Aun así el prisma marxista de la explotación sigue siendo la mirada hegemónica para entender las relaciones comerciales con Estados Unidos. A pesar de ello, las comparaciones son inevitables con el vecino del norte, al punto de intentar emular siempre su nivel de desarrollo e incluso sus instituciones. Las constituciones promulgadas durante la independencia en Latinoamérica, tomaron muchos aspectos del constitucionalismo norteamericano. El problema ha sido que a pesar de copiar en gran medida su modelo de Estado y economía, los resultados no han sido los mismos. La debilidad institucional ha sido el problema principal, por el contrario, la fortaleza de las instituciones norteamericanos han sido fundamentales en su éxito.

De allí que en palabras de Carlos Rangel, "...el adelanto y la superioridad nacional de los norteamericanos los sentimos como una ofensa, la cual se mitiga si podemos persuadimos de que los EE.UU. han triunfado a costa de nosotros" (Rangel, 2006, p. 81). No aceptar el éxito ajeno por virtudes propias, es el equivalente a negar el fracaso propio. La historia de Estados Unidos con relación a América Latina se cuenta igual que la española, con la narrativa del despojo y expansionismo territorial. Pero no todo ha sido atraso como se quiere hacer ver. Las relaciones comerciales con Estados Unidos han sido beneficiosas. Es coincidente el planteamiento de que en el siglo XX América Latina se incorporó de manera mucho más directa al capitalismo mundial cada vez mejor articulado, incluido sobre todo con la economía norteamericana. ¿Cuáles han sido los resultados?

La tasa de crecimiento económico de América Latina, por ejemplo, es en este momento y ha sido por mucho tiempo superior a la tasa de crecimiento en el siglo XIX de los países hoy capitalistas avanzados, que fue de aproximadamente 2 por ciento al año; mientras que Latinoamérica creció entre 1935 a 1953 a una rata de 4,2 anual y de 1945 a 1955 a la tasa de 4,9 por año (Rangel, 2009, p. 85). 
Latinoamérica ha reportado crecimiento a lo largo del siglo XX, con períodos de auge y declive como es natural en toda economía. Algunos problemas han estado referidos a un gasto público excesivo, con niveles de endeudamiento relativamente altos. Afrontar el pago de las acreencias muchas veces ha implicado programas de ajuste que han sido rechazados por la población.

Esto sin contar los numerosos casos de corrupción, debido a una débil estructura institucional. A pesar de reconocer la mala gestión de algunos gobiernos en Latinoamérica, siempre el culpable preferido ha sido el imperialismo americano. Con las tesis marxistas, se quiso responsabilizar también a los presidentes de turno, al catalogarlos de vendidos a los intereses del capital trasnacional.

De esa forma, la tesis de una oligarquía política aliada a la burguesía nacional e internacional, representada principalmente por Estados Unidos ofreció una teoría integral para definir el fracaso de la región. El caso cubano resulta ejemplar, con la revolución cubana liderada por Fidel Castro, y el posterior bloqueo comercial con Estados Unidos, dio una excusa perfecta de lucha al nuevo régimen comunista.

No era la siempre inviabilidad del socialismo lo que provocaba la pobreza en una isla que antes tuvo una prosperidad importante, sino el ataque imperial de los norteamericanos. Esta retórica fue seguida por otros gobiernos latinoamericanos, el caso de Allende en Chile es ilustrativo.

Una vez más Estados Unidos, y más específicamente la CIA, son señalados como el causante principal de la caída del gobernante y el malestar de la economía chilena. De esa manera Carlos Rangel expone: "El gobierno de Allende, con su fracaso y trágico colapso contribuyó en forma importante y seguramente indeleble al repertorio de inexactitudes de que se nutre la conciencia latinoamericana" (Rangel, 2006, p. 100). El fracaso de los ensayos comunistas en el continente se debe siempre a ese intervencionismo americano que no está dispuesto a aceptar la emancipación de los pueblos.

A través de la crítica a la CIA y un documento que expone como intentaron sabotear la economía chilena, han terminado de consagrar el papel mítico de esta organización como agente eficaz y perverso de casi todo cuanto anda mal en el Hemisferio (Rangel, 2006).

De esa forma, gobiernos despóticos como el de Fidel Castro en Cuba, o actualmente Maduro en Venezuela, con la excusa de combatir a agentes de la CIA, pueden encarcelar a gran cantidad de disidentes y críticos de sus políticas. Al fin de cuentas, todas las interpretaciones equivocadas realizadas hasta ahora, responden a fines políticos muy bien utilizados por los gobernantes, sobre todos exacerbados por los más autoritarios. La lucha antiimperialista ha sido una excusa perfecta para imponer tiranías. Las últimas de más reciente data, denominadas socialismo del siglo XXI.

\section{El marxismo y el socialismo en Latinoamérica: la apología a la revolución}

Cualquiera que estudie la historia de las ideas políticas o historia intelectual, se dará cuenta como Latinoamérica ha recibido una fuerte influencia del marxismo. Entre las muchas razones para explicar su positiva receptividad, está el hecho de que ofrece una explicación que coloca en posición de víctimas a las llamadas clases oprimidas. 
Esta idea permite fusionar la larga tradición de la leyenda negra hacia España, y más recientemente el sentimiento antinorteamericano, sobre el argumento de estar en un mundo que promueven desigualdades y explotación hacia los países más pobres de la región.

Como señala Moisés Naím, "la idea tradicional de que es inevitable que las desigualdades económicas persistan e incluso empeoren hace que todos seamos, en cierto modo, marxistas" (Naím, 2016, p. 71). La revolución socialista es la única capaz de liberarnos de esa condición de dependencia y volvernos más iguales. Sobre todo los planteamientos de Lenin sobre el imperialismo fueron los más tomados en cuenta en Latinoamérica.

El marxismo en su versión más ortodoxa fue lo predominante. Como ahora el centro del capitalismo mundial era Estados Unidos, Latinoamérica por su cercanía con el vecino del norte, sería puesto como una región que ejemplifica la pobreza y la expoliación víctima del imperialismo occidental norteamericano.

Tanto llega la influencia del marxismo en el siglo XX, que incluso Carlos Rangel previó en un futuro la aparición de un nuevo régimen socialista equivalente al de Cuba en Latinoamérica: "¿Llegará el día en que la URSS o China, los centros de la revolución socialista mundial, puedan, en cambio, contar en Latinoamérica con otros puntos de apoyo sólidos además de Cuba? " (Rangel, 2006, p. 186).

No era descabellado pensar en tal posibilidad, puesto que nadie imaginó nunca en su momento a Cuba como un satélite de la Unión Soviética. La caída de la URSS no impidió que el comunismo se siguiera expandiendo en el mundo. La tesis de que no fue verdadero socialismo se difundió a tal punto que inmediatamente después surgieron nuevas propuestas para volver a ensayar un sistema socialista.

Dieterich (2008), plantea sus tesis del socialismo del siglo XXI, que fue acogida luego por el gobierno chavista. Hoy Venezuela sin lugar a dudas se ha vuelto un país fundamental en la expansión del socialismo por Latinoamérica, conjuntamente con Cuba que sigue siendo relevante para lograr tal objetivo.

Esto era fácil de prever ante todo, el conjunto de ideas que Carlos Rangel vio y denunció en su momento, una región que sataniza el capitalismo, la competencia, que no asume responsabilidades, llena de mitos y alegorías en torno a gobiernos y líderes autoritarios, no podía elegir un camino diferente al de una revolución socialista.

Estados Unidos fue un contenedor de la expansión del comunismo por el mundo, esta lucha no se le reconoce nunca a la potencia del norte. Corea del Sur fue salvada de caer en las manos del régimen de Corea del norte gracias a la intervención americana. El contraste entre la Corea capitalista y la comunista es notorio, la primera muy próspera y la otra altamente empobrecida.

Las alianzas con Estados Unidos no han resultado del todo negativas para los pueblos, pero se cuenta la historia desde visiones maniqueas. El éxito está en cortar las relaciones de dependencia con el vecino del norte. Uno de los más grandes éxitos de Fidel Castro fue:

lograr en la práctica, a 150 kilómetros de las costas norteamericanas, en una de los países más estrechamente vinculados a los EE.UU., una de las victorias más importantes y espectaculares dentro de la perspectiva de las tesis leninistas sobre el rol de los países coloniales y dependientes en la destrucción del orden capitalista mundial" (Rangel, 2006, p. 204). 
Aunque Fidel cambió la dependencia hacia la Unión Soviética, y Chávez lo hizo con los rusos y chinos, lo que cuenta al parecer es librarse de la odiada potencia de Estados Unidos, porque es la causante de todos los problemas de las naciones latinoamericanas por expandir el sistema capitalista opresor.

El sostenimiento del régimen cubano aun después de caído el muro de Berlín, se constituyó en una esperanza para los comunistas del mundo. Una nueva isla paradisiaca que nuevamente respondiera al ideal del buen salvaje, una sociedad no contaminada por los errores del comunismo soviético, aunque bien que usó el mismo guion estalinista, pero ajustado a la realidad cubana.

Carlos Rangel expone acertadamente, en torno a ese nuevo mito sobre la Cuba comunista como:

La Revolución Cubana (como antes -y todavía- la Revolución China) vino a responder por un momento a esa ilusión. Y dentro de ella, no tanto Fidel (cuya figura de "político" y de hombre de poder traspasaron desde muy temprano, la máscara "buen-revolucionaria" de la barba y el uniforme ajado y sin insignias) como el Che Guevara, con sus teorías sobre la función purificadora de la guerrilla y el "hombre nuevo" (Rangel, 2006, p. 207).

El hombre nuevo, un ser humano alejado de todos los vicios de la civilización occidental y del capitalismo explotador. La idea consumado del buen salvaje al buen revolucionario. Carlos Rangel explica el ideal de nuevo guerrillero promovido por el Che Guevara: "El guerrillero debe ser como un santo de la revolución, superior a los demás hombres no sólo en valor personal, y conciencia revolucionaria, sino también en bondad y simpatía hacia los oprimidos" (Rangel, 2006, pp. 207-208).

El guerrillero cambiaría el mundo, haría posible la revolución, su función era liberar al pueblo de la opresión de los gobiernos oligárquicos y burgueses. Las bajas civiles provocadas por su accionar serían solo daños colaterales, sacrificios necesarios para alcanzar un bien mayor.

Defender a las victimas históricas es su papel principal. Al fin de cuentas los comunismos siempre se han caracterizado dentro de sus discursos, por hacer una apología de la guerra, la violencia simbólica y de hecho por medio de sus acciones para alcanzar el poder político.

El Che Guevara no tuvo éxito en sus propósitos, murió en Bolivia. No pudo emular lo acontecido en Cuba, y su sueño de expandir el comunismo por América Latina no pudo ser concretado en su momento. Pero el Che triunfa como personaje mítico, como mártir de la revolución.

Después de todo, el realismo mágico presente en el imaginario latinoamericano, el constante culto a los héroes, y ahora en el siglo XXI a las víctimas, los hace proclives a idealizar personajes pese a sus demostradas acciones asesinas. Pero los hechos y las ideologías no se mezclan. Carlos Rangel advertía como: "...la realidad sociológica ha derrotado a la teoría. Los jóvenes latinoamericanos que persisten, inspirados por el culto a Fidel y al Che Guevara, en emplear la "lucha armada" operan desde hace varios años casi exclusivamente en las ciudades" (Rangel, 2006, p. 215). 
Las nuevas generaciones no quieren irse a las montañas a emprender una acción armada, lo hacen en las ciudades, muchas veces desde los recintos universitarios, con protestas, algunas de tipo violenta, para intentar combatir el modelo explotador capitalista. El éxito del socialismo más que por la fuerza de las armas, ha sido gracias a la aceptación de sus ideas.

Como expresa Ismael Saz, la utopía socialista tendría un poderoso atractivo, hasta el punto de que el comunismo pudo convertirse en el gran mito del siglo XX (Saz, 2013, p. 458). Aunque sobrevive como ideología, el socialismo tuvo que mutar en sus estrategias, por eso los gobiernos socialistas del siglo XXI en Latinoamérica lograron llegar por la vía de los votos.

Chávez fracasó en Venezuela en su movimiento armado, pero fue efectivo en el convencimiento a una población que quería un modelo más "justo" e igualitario, y terminó en una debacle generalizada. El Che Guevara también fracasa como guerrillero, no obstante, el personaje es solo recordado como un luchador a favor de la justicia, el representante perfecto del buen revolucionario. Su imagen ha sobrevivido a su deceso, ha tenido gran éxito entonces como mártir de los revolucionarios modernos.

Entre otras razones, porque el Che estuvo dispuesto a sacrificar su vida por el bien común. Después de todo, la retórica comunista siempre menciona la importancia y la necesidad del sacrificio para alcanzar la revolución. Dar la vida de ser necesario para alcanzar un ideal mucho más elevado.

Sobre los peligros ideológicos de hablar de sacrificio, ya Rand advertía sobre lo pernicioso de esa idea: El hombre que te habla de sacrificios está hablando de esclavos y amos, e intenta ser el amo (Rand, 1975). Pero un buen revolucionario debe estar dispuesto a sacrificarse por alcanzar un mundo más justo.

Bajo esa retórica, se alaba todo proceso de resistencia al imperialismo capitalista, y es la guerra de Vietnam uno de los procesos más ensalzados por el heroísmo en la lucha. A partir de eso muchos han soñado con revivir varios Vietnam en América Latina.

Carlos Rangel expone irónicamente un subtítulo en su texto denominado: "Uno, dos, tres, muchos Vietnam". Siempre el objetivo es emular glorias y victorias pasadas. Pero lo único de glorioso que tuvo esa guerra fue impedir el control norteamericano del territorio, aunque a costa de la vida de gran parte de los vietnamitas.

Nuevamente, el ideal del sacrificio y la apología de la guerra son permanentes. Pero llevar a cabo o imitar ese proceso no es nada fácil. ¿Quién, o quiénes, serán, después de esto, los promotores, conscientes o inconscientes, de los uno, dos, tres, muchos Vietnam con que soñaba el "buen revolucionario" Ernesto Guevara para América Latina? (Rangel, 2006, p. 222).

En Venezuela, el gobierno chavista actual, ante una supuesta posible intervención norteamericana al país petrolero, ha amenazado con volver a crear un nuevo Vietnam en Latinoamerica. El discurso del buen revolucionario si bien adquiere nuevos matices, no deja de lado la pervivencia de ciertos mitos aun en contextos completamente diferentes.

Al parecer su recurrente uso demuestra su aceptación en los nuevos jóvenes mentes revolucionarias. Incluso en las personas mayores, el anhelo de hacer realidad sus sueños frustrados de juventud, y finalmente, poder enfrentarse valerosamente al imperio que han criticado toda la vida, se vuelve una aspiración deseable. El marxismo se convierte en una ideología a favor del resentimiento, y por eso logra ser tan exitosa. 


\section{Vigencia de la obra de Carlos Rangel}

Las ideas políticas en Latinoamérica no han evolucionado mucho desde que Carlos Rangel escribió su obra. Son notables los mismos defectos, el socialismo del siglo XXI en la región se basó en un resurgir del mito del indigenismo. Es una visión claramente antioccidental sobre nuestras sociedades que intentan construir proyectos autónomos.

Luis Alberto Buttó (2018), argumenta que la democracia no proviene precisamente del mundo indígena, es claramente una herencia del pensamiento Occidental, negar su aporte da pie para justificar proyectos de corte autoritario con la intención de acabar con la República como ha sucedido recientemente en Latinoamérica, para ahora sí construir la utopía que fue robada desde que llegaron los europeos.

No se ha abandonado el resentimiento por el pasado, menos la oposición entre el conquistador, lo europeo, y la formación de los Estados-nación en Latinoamérica. Ya Carlos Rangel decía al respecto:

Pero en la práctica, lo que se busca actualmente es potenciar al máximo el mito del "Buen Salvaje" por lo que tiene de virulencia nacionalista, antiimperialista buen-revolucionaria en sociedades que de hecho deben relativamente muy poco al pasado precolombino, y en las cuales el indio o bien está totalmente ausente, 0 bien arrastra una existencia pasiva y marginal (Rangel, 2006, p. 280).

Hoy en día, mucho más que en el momento de escribir Carlos Rangel su texto, hay un exponencial crecimiento del mito del Buen Salvaje. Es así como en las constituciones de Bolivia, Ecuador y Venezuela hubo un reconocimiento a los derechos de los pueblos indígenas y una retórica antioccidental, cimentada en nuevas teorías como el giro decolonial.

Un empeño por crear proyectos supuestamente autóctonos, alejados de las formas de dominación occidental. Nadie niega que a los indígenas se les ha violado parte de sus derechos a lo largo de la historia, pero actualmente, piden sobre todo privilegios para ellos, sin corresponsabilidad de deberes en muchos casos. La mayoría de sus economías son de subsistencia, con la permanencia en algunos casos de formas de producción como el conuco. No puede construirse un proyecto que entonces tome como referencia, solamente, la herencia de las llamadas sociedades originarias.

La democracia es criticada por ser parte de la herencia de dominación occidental. En su lugar, se usan máscaras como democracia protagónica, participativa, radical, social 0 socialista, y toda una serie de adjetivos para intentar construir un nuevo modelo político que coarte la libertad.

La figura de Chávez ha sido alabada por parte de algunos grupos marxistas al punto de quererlo vender como una nueva versión del buen revolucionario en Latinoamérica. Desde su muerte en el 2013 el chavismo en Venezuela lo ha idealizado al punto de querer convertirlo en un mártir de la revolución, el hombre que a pesar de estar enfermo se mantuvo siempre en pie de lucha para asegurar la permanencia del proceso socialista.

Carlos Rangel advirtió sobre los peligros de alabar a ciertos líderes, así como los riesgos del populismo y otras ideologías intervencionistas, y mantuvo una defensa a ultranza de los principios básicos de libertad, la democracia, el estado de Derecho y el libre comercio, que 
alguien, mirando en retrospectiva, dijo de él que había sido "el primer antichavista del mundo" (Socorro, 2018).

Más que el primer antichavista, adelantándose a lo que sería el autoritarismo de Chávez, fue uno de los más importantes anticomunistas en general en un contexto donde esa ideología ganaba mayores espacios. El resurgir del sentimiento antimperialista también ha sido muy significativo en los últimos años.

Al igual que la condena moral al capitalismo por ser un sistema explotador. Es increíble como no hay una evolución de las ideas políticas, en lugar de refutar o desmitificar tales aseveraciones, con el paso del tiempo se han reforzado.

Las sociedades latinoamericanas exigen cada vez más igualdad, pero no libertad, y cuestionan los fundamentos del llamado "neoliberalismo". De esa forma, desean gobiernos más intervencionistas en materia económica, que se encarguen de repartir la riqueza. El uso demagógico de la palabra pueblo es muy empleado.

La búsqueda de permanentes utopías idealizadas, el fin de los conflictos, de las desigualdades y de la explotación, pero siguiendo a líderes mesiánicos, al margen de las instituciones del Estado de derecho, y con el mismo resentimiento histórico de carácter racial, y ahora se ha sumada la retórica de la desigualdad de género.

Discursos que se empeñan en fomentar antagonismos y divisiones en las sociedades para facilitar su dominación. Pero encubiertos bajo un manto de resarcimiento de los excluidos, pero más que eso, se promueve el revanchismo hacia los grupos calificados de manera genérica como opresores.

Hoy la obra de Carlos Rangel al igual que en su momento debe tomarse como un llamado a la defensa de la sociedad occidental, de los valores positivos fundamentales a favor de la libertad, y de buscar caminos modernos para lograr el progreso. Venezuela es el caso actual más notable del fracaso de un proyecto político de corte comunista, pero idealizado por buena parte de la intelectualidad.

El número de exiliados venezolanos en el exterior es de los más elevados de la historia. Ya Carlos Rangel señaló sobre los comunismos el hecho sin precedentes de una emigración masiva:

...son los únicos sistemas políticos en la historia de los cuales ha sido preciso impedir por la fuerza que la gente huya, dispuestos a dejar todo atrás, no sólo bienes, sino la familia más inmediata, viniendo a resultar el exilio voluntario no un gesto excepcional, doloroso de una ínfima minoría principista o muy activa políticamente, sino como una esperanza loca de casi todo el mundo, aunque casi imposible de alcanzar, salvo para algunos pocos bienaventurados (Rangel, 2006, pp. 458-459).

Por un lado, algunos niegan u omiten esa realidad del exilio masivo, incluyendo los exiliados cubanos que huyen arriesgando sus vidas en balsa, y por el otro, responsabilizan de esa situación a los Estados Unidos. Aunque otros intelectuales prefieren asumir simplemente que no fueron verdaderos sistemas socialistas.

Esto es muy repetido hoy en día en el caso venezolano y de otros países de Latinoamérica como Bolivia y Ecuador. Sobre todo en Venezuela con el peor resultado económico y social de la región, es común escuchar que no hubo socialismo, porque los 
resultados nunca son iguales al estado ideal propuesto. $O$ en su defecto, se asumen que todos los problemas son productos del imperialismo americano.

De esta forma, en el futuro se seguirán justificando otros ensayos y nuevas utopías que históricamente nos han mantenido en el subdesarrollo, negados a aceptar nuestras equivocaciones, y la puesta en práctica de ideas erróneas, defendidas principalmente a través del manto de las ideologías y no de las realidades. El Marxismo sigue estando muy presente en la región con sus lecturas tergiversadas sobre los problemas latinoamericanos.

\section{Conclusión}

El texto de Carlos Rangel del Buen Salvaje al Buen revolucionario es un libro innovador, disecciona diferentes mitos construidos a lo largo de las décadas en Latinoamérica. Leerlo a la luz de los problemas contemporáneos, ejemplifica su vigencia para comprender realidades cada vez más complejas.

Es un libro si se quiere que continúa siendo rechazado por parte de la intelectualidad latinoamericana, enfrascada todavía en construir el socialismo real, autóctono y antimperialista. Permanentemente buscando un nuevo líder revolucionario, Chávez fue la mejor expresión de un intento por copiar las hazañas heroicas de Fidel Castro y el Che Guevara.

Mantuvo la retórica de un discurso antioccidental, anticapitalista, indigenista, pro socialista, igualitarista, a favor de los oprimidos, opuesto a las oligarquías y con un fuerte rechazo a la herencia colonial. La búsqueda de la construcción de una nueva democracia perfecta y utópica donde todos puedan ser felices.

Carlos Rangel defendió los cimientos de la democracia occidental, de la herencia colonial, pese a todas sus imperfecciones, denunció al marxismo-socialismo como lo qué es, un modelo que solo ha servido para la opresión de los pueblos en nombre de falsos ideales. De igual forma buscó confrontar aquellas tesis sobre el imperialismo y la pobreza de las naciones latinoamericanas a partir de la explotación capitalista.

Fue un llamado de atención, para que las sociedades asuman sus responsabilidades en su falta de progreso, por no consolidar instituciones políticas estables, y rechazar el libre mercado por ser supuestamente la expresión de la explotación. El Estatismo y el infantilismo político expresado en el culto a ciertas personalidades, muchas de ellas nefastas como Fidel Castro 0 el Che Guevara, nunca iba a permitir a los latinoamericanos salir del atraso.

El mito del buen salvaje y del buen revolucionario siguen vivos en Latinoamérica, casi todas las denuncias y críticas realizadas por Carlos Rangel son aplicables en la actualidad. Por tanto, su obra valientemente escrita merece una mayor discusión, debate y reflexión, porque dan luz sobre complejos problemas históricos de nuestras naciones llenas de resentimiento y sin ser capaces de asumir sus defectos.

\section{Referencias Bibliográficas}

Almandoz, Arturo (2019). Carlos Rangel: desmitificando el buen revolucionario. Extraído de https://prodavinci.com/carlos-rangel-desmitificando-el-buen-revolucionario/. Consulta: $01 / 07 / 20$.

Altez, Rogelio (2011). Independencia, mito genésico y memoria esclerotizada. Pp. 19-56. En: Inés. Quintero (Coordinadora). El relato invariable. Independencia, mito y nación. Editorial Alfa. Venezuela. 
Buttó, Luis (2018). La antinomia Democracia-Socialismo del Siglo XXI. Pp. 19-80. En: Buttó, Luis, Olivar, José (Compiladores). Entre el ardid y la epopeya: Uso y abuso de la simbología en el imaginario chavista. Editorial Negro Sobre Blanco. Venezuela.

Dieterich, Heinz (2008). El Socialismo del Siglo XXI. Edición de autor. México.

Gruzinski, Serge (1999). El pensamiento mestizo. Paidos. España.

Lenin, Vladimir (2000). El imperialismo fase superior del capitalismo. Editorial Debarris. España.

Naím, Moisés (2016). El fin del poder. El Nacional. Venezuela.

Rand, Ayn (1975). El Manantial. Editorial Planeta. España.

Rangel, Carlos (1982). El tercermundismo. Monte Ávila editores. Venezuela.

Rangel, Carlos (2006). Del buen salvaje al buen revolucionario. Monte Ávila editores. Venezuela.

Revel, Jean (2003). La obsesión antiamericana. Dinámica, causas e incongruencias. Urano Tendencias. España.

Roca, Elvira (2018). Imperiofobia y leyenda negra Roma, Rusia, Estados Unidos y el Imperio español. Epublibre. España.

Rousseau, Jean (2000). Emilio o la educación. Fondo de cultura económica. México. Saz, Ismael (2013). El comunismo. Pp. 458- 499. En: Casassas, Jordi (coord). La construcción del presente. Historia del mundo desde 1848 hasta nuestros días. Editorial Planeta. España.

Serfaty, Isaac (2010). Actualidad del mito de la Independencia: en búsqueda de sentido en la babel fragmentada. Pp. 21-45. En: Detrás del mito. La Independencia de Venezuela 200 años después. Banesco. Venezuela.

Socorro, Milagros (2018). El primer antichavista del mundo. Extraído de https://prodavinci.com/el-primer-antichavista-del-mundo/. Consulta: 01/07/20. 